\title{
'Boosting resilience' and 'safeguarding youngsters at risk': Critically examining the European Commission's educational responses to radicalization and violent extremism
}

\author{
Eleni Christodoulou (D)
}

\section{How to cite this article}

Christodoulou, E. (2020) "Boosting resilience" and "safeguarding youngsters at risk": Critically examining the European Commission's educational responses to radicalization and violent extremism'. London Review of Education, 18 (1): 18-34. https://doi.org/10.18546/LRE.18.1.02

Submission date: 23 May 2019

Acceptance date: 11 November 2019

Publication date: 1 March 2020

\section{Peer review}

This article has been peer reviewed through the journal's standard double-blind peer review, where both the reviewers and authors are anonymized during review.

\section{Copyright}

(C) Copyright 2020 Christodoulou. This is an Open Access article distributed under the terms of the Creative Commons Attribution Licence (CC BY) 4.0 https://creativecommons.org/licenses/by/4.0/, which permits unrestricted use, distribution and reproduction in any medium, provided the original author and source are credited.

\section{Open access}

Research for All is a peer-reviewed open-access journal. 


\title{
'Boosting resilience' and 'safeguarding youngsters at risk': Critically examining the European Commission's educational responses to radicalization and violent extremism
}

\author{
Eleni Christodoulou* - Georg Eckert Institute for International Textbook \\ Research, Braunschweig, Germany
}

\begin{abstract}
Despite the Radicalisation Awareness Network (RAN) being tasked with being a core policy tool of the European Union and helping to shape its research funding agenda on preventing violent extremism, very little is known about how it operates, the practices and activities it engages with and the discourses it mobilizes to do so. This study fills this gap through an in-depth investigation into RAN's working group on education, critically examining the construction and enactment of discourses and practices related to the prevention of violent extremism through education. Combining a critical engagement of organizational practices with a discourse analysis of the various RAN EDU outputs, such as manifestos, policy papers and videos, it offers an examination of the discursive terrain of the European Commission, revealing the normative values and ideological assumptions underpinning it, as well as the subject-positioning of students and teachers involved.
\end{abstract}

Keywords: preventing violent extremism, counterterrorism, radicalization, resilience, Radicalisation Awareness Network, European Commission

\section{Introduction}

As a response to diverse processes of radicalization, evolving forms of violent extremism, and a perception that there is a linear link from the former to the latter, organizations (local, national, regional and international) have increasingly been calling for a multilevel approach that utilizes the power of youth and education. Commonly known as 'PVE-E' (Preventing Violent Extremism through Education), this approach reflects a wider sociopolitical discursive shift in the international agenda on addressing violent extremism: first, a move from mere security, intelligence and military operations - that is, 'hard power' - to ones that utilize 'soft power' and focus on winning over (or back) hearts and minds; second, a recognition that prevention is more effective than attempts to intervene after an individual has been radicalized, and that this is best done through a holistic approach that places the education sector at the forefront; and third a consideration of young people not just as victims or perpetrators, or mere recipients of these policies, but also as agents of positive change. The United Nations Security Council (UNSC) Resolution 2250 on Youth, Peace and Security passed in 2015, for example, emphasizes the importance of youth participation in decision-making processes on global security issues and has been hailed as the 'first international policy 
framework that recognizes the positive role young people play' in preventing and countering violent extremism (Youth4Peace, 2016). Following this, former SecretaryGeneral Ban Ki-moon's 2015 UN Plan of Action to Prevent Violent Extremism called for more 'comprehensive' and 'systematic preventative measures', pointing to education as a priority area for taking action, and giving an explicit mandate to UNESCO for doing so (United Nations General Assembly, 2015: 2). Such international developments operated as 'fundamental step[s] in institutionalizing and internationalizing PVE', mainstreaming it both within UN discourses and practices, and externally, among funders, policymakers, NGOs, educators and practitioners (Christodoulou and Szakács, 2018: 25).

Against this backdrop, and within the framework of The European Agenda on Security (European Commission, 2015), the European Union (EU) also began giving greater and more consistent emphasis to the role of education as a tool to prevent radicalization and violent extremism. The Agenda set out a shared approach for the $\mathrm{EU}$ and its member states, and emphasized the role of 'education, youth participation, interfaith and inter-cultural dialogue' in promoting 'common European values' in a multi-agency and cross-sectorial approach (European Commission, 2015: 15). One must also keep in mind that 2015 was what Cas Mudde (2016: xxiii) has referred to as Europe's annus horribilis, a horrible year with many events that increased disillusionment with the EU, including the so-called refugee crisis, which exacerbated fears of 'importing' extremist ideologies. The European Commission (EC) - the EU's executive arm - has since been proposing, overseeing and implementing EU policies related to educational responses to violent extremism. On the level of non-formal education, the EC for instance has funded projects on preventing marginalization and violent radicalization under the EU Work Plan for Youth 2016-2018, as well as within the Erasmus + youth programme, SALTO-YOUTH, aimed at both youth workers and policymakers through the active involvement of young people. When it comes to formal education, the lead organization assigned with the mandate of PVE-E is RAN EDU, the Radicalisation Awareness Network's (RAN) working group on education. RAN is an EU-wide umbrella network set up by the EC in 2011 and, operating through nine working groups, it aims to bring together front-line practitioners such as teachers, police officers, social workers and NGOs to exchange new insights and address issues related to violent extremism and radicalization.

The focus of the present study is an in-depth investigation of RAN EDU through a critical engagement with its practices and discourses, including an analysis of all its outputs from its launch in 2015 until 2019. How does RAN EDU operate? How is it involved in supporting and enacting PVE-E and what are the implications of these working practices? Which discourses of violent extremism and radicalization are mobilized, what is the subject-positioning of students and teachers, and what are the normative, pedagogical and ideological assumptions underpinning these discourses? Is there evidence of a critically reflective approach, or are there problematic and contradicting assumptions that might be counterproductive? Interrogating the discursive terrain of RAN EDU is of particular significance in the newly emerging area of PVE-E, where these discourses have the power to influence the policies and practices of stakeholders such as teachers, NGOs and policymakers, but also have a direct impact on young people. It is also an important task given the subjective, politically loaded and contested nature of concepts such as 'extremism', 'radicalization', 'resilience' and 'safeguarding' (see Neumann, 2013; Busher et al., 2017; Heath-Kelly and Strausz, 2019). These concepts are used to legitimize counter-extremism agendas and are referred to in educational policies within such pragmatic, depoliticized and inevitable discursive frames that to 
question them seems not only counter-intuitive but also anti-educational - in stark antithesis with the moral and professional duties of an educator.

The next section offers a brief survey of an emerging research field that has developed over the past five years, described here as 'critical approaches to PVE-E', to which the article seeks to contribute. An outline of the data collection methods and analysis follows, after which the empirical findings are presented in two parts. The first part is a critical engagement with the various practices of RAN EDU. The second empirical section offers a critical examination of the discursive terrain of RAN EDU and by extension the European Commission - through an analysis of the various RAN EDU outputs, such as manifestos, policy papers, ex-post papers and videos.

\section{Critical approaches to PVE-E}

The field of education and violent extremism has grown exponentially over the past five years. This indeed coincides with the aforementioned shift in international organizations' policies, which undoubtedly had an effect on academic literature in this area. There was a proliferation of funding for new networks, projects, conferences, expert meetings and workshops, as well as various outputs such as guidebooks and toolboxes, all of which offered opportunities for academics to participate but also to critically engage with (see Christodoulou and Szakács, 2018: 25-35). Arguably, an even more important trigger was given by Britain's controversial Prevent strategy (part of its broader counterterrorism strategy called CONTEST), which has been heavily criticized for leading to discrimination against the Muslim community, exacerbating Islamophobia and racism, violating freedom of expression and stigmatizing young children perceived to be 'at risk' of radicalization. Debates intensified after 2015, when a statutory duty was introduced making it mandatory for teachers to report on possible students they deem as 'vulnerable' to radicalization or else face disciplinary or legal action. This has led to a range of concerns from scholars who adopted what can be called 'critical approaches to PVE-E'. These scholars challenge the assumptions that underpin much of mainstream PVE-E thinking (going beyond the borders of the UK) and argue that associated practices 'unintentionally, might be driving young people towards "extremism" rather than combatting it - through lack of reflexivity, humility, historical memory and nuance' (Novelli, 2017: 835-6).

Such concerns include stigmatization, discrimination and infringement of human rights, the breach of education's autonomy by security agendas, and the implications of such policies on the relationship of trust between the teacher and the student (O'Donnell, 2016; Holmwood and O'Toole, 2018). Indeed, much of recent literature is concerned with the ethical, pedagogical, social and political repercussions of the socalled securitization of education (used in the vast majority of cases to mean the invasion of security agendas into education settings, and not in the sense of 'securitization' as used in the Copenhagen School of International Relations). Researchers have shown how, situated within the so-called 'war on terror' and broader counterterrorism agenda, much of the PVE-E discourses have not been immune to picking up its often empirically unfounded assumptions - for instance, of the causal connection between radicalization and violent extremism (strongly criticized by Kundnani, 2012), which justifies the need for 'ideational' control and surveillance - and in so doing negatively affecting students' lives and school or university experiences, especially those treated as 'suspects' (Nguyen, 2014; Brown and Saeed, 2015; Thomas, 2016; Panjwani et al., 2018). Not all scholars (within this approach) share a critical stance to the same degree: some are highly critical of the (ab)use of education to achieve security objectives 
and emphasize the need 'to preserve education's autonomy from security agendas' (O'Donnell, 2016: 60), while others maintain that it is possible 'to safeguard young people without securitising' through a 'justice-sensitive' approach that promotes human rights while ultimately contributing to national security (Davies, 2016: 1).

In addition to security, another thread that appropriately undercuts some of the literature is the role of power politics, control and the subject-positioning of students. The latter is presented both in terms of students' assigned agency, role and power in the PVE-E agenda but also in what constitutes a democratic, moderate and, hence, desired and 'free from surveillance' student subject. Studies have shown how the simplistic victimization/villainification of students is conceptually and empirically weak: the 'victim' label overlooks their active agency, while the 'villain' label - assigned to any student who may espouse radical values - risks ignoring the fact that a lot of young students 'explore modes of engaging with radical and alternative perspectives' (Sieckelinck et al., 2015: 331) as part of growing up and constructing their identity, or that radical views have historically been the fuel for positive societal change. Less has been discussed in terms of the subject positioning of teachers, which, as I illustrate later, is an integral part of the student-teacher bond as constructed in PVE-E discourses, and therefore deserves more attention. As Roozbeh Shirazi (2017: 4, emphasis added) aptly points out:

investigations of the interplay of extremism and schooling should not constitute an analytical field divorced from the critical study of politics ... and the contests to delimit who counts as a meaningful political subject in 'Western' societies experiencing demographic tension and transition.

Recently, studies have also deployed psychopolitical and postcolonial concepts to illuminate the construction of white supremacist subjectivities through state-led curriculum policy with an emphasis on national values. This construction operates, on the one hand, as a 'defence mechanism against perceived threats to white privilege, by normalising a racialized state-controlled social order', while on the other hand, it fails to acknowledge 'the normalised state violence and radical exclusions on which liberal values have been built' (Winter and Mills, 2018: 1, 15).

Most of these studies, however, remain at country-level, whether they provide an in-depth analysis at the state level, or an overview of educational initiatives in a variety of countries, as has been done in a recent review that examined how educational institutions in 23 countries are addressing violent extremism (Davies, 2018). It is pertinent to study international organizations, and to probe the normative values, ideological assumptions and pedagogies that they endorse, as they have the power to influence education policies on a global scale and at regional, national and local levels (Rizvi and Lingard, 2010). An exception to this tendency in the literature is a stout and scathing critique of the P/CVE (Preventing/Countering Violent Extremism) agenda of organizations such as the UN and the EU: the study shows how the agenda of P/CVE, largely based on UK and Dutch models before being exported to other parts of Europe and the world, has led to the infringement of human rights and the instrumentalization of civil society (Kundnani and Hayes, 2018). However, this study does not specifically engage with education. Surprisingly, only two studies have so far studied the educational response of international organizations to violent extremism - that is, the type of discourses and practices they promote, support and enact for and through the education sector. One of these is a mapping of the work of 12 key international organizations in PVE-E in a comparative perspective, which has identified the EC as one of the 'primary organizations' (Christodoulou and Szakács, 2018), while 
the other one undertakes a critical discourse analysis of one key document of RAN, the so-called RAN Collection of Approaches and Practices - an evolving collection of various projects of PVE in Europe - and specifically its chapter on education (Mattsson et al., 2016). The present article extends this work by undertaking an analysis of all the outputs (documents and videos) as well as practices of RAN EDU. Given that Mattsson et al.'s study was published only a year after the creation of RAN EDU, and looked at a single (albeit key) document, it is worthwhile to take a broader look at RAN EDU's work over the past four years.

\section{Methodological outline}

The article adopts a constructivist approach to understanding the behaviour of international organizations: they have authority to make rules and formulate policies, to exercise normative power, to create and define new agendas and shared international tasks, and to disseminate these around the globe, thereby not only regulating social reality but also helping to construct it. This approach provides a theoretical basis for highlighting the agency they have, the disciplinary power (used in a Foucauldian sense) they envisage and exercise, and their at times dysfunctional behaviour (Finnemore, 1993; Barnett and Finnemore, 2004). I employ a discourseethnographic methodology, that is, one that views institutional spaces as complex sites of production and reception of discourses (Wodak and Krzyżanowski, 2008; Krzyżanowski, 2011), going beyond the traditional limits of ethnographic and discourse analysis. In other words, it pays attention to the inter-constitutive relation between discourses and the organizational context and practices.

The four sources of data were:

(1) RAN EDU outputs (texts and videos)

(2) EU documents, such as charters, rules of procedure and policy legislation

(3) participant observations from a RAN EDU session

(4) discussions with other RAN EDU participants.

The outputs on education were collected from the RAN EDU website in March 2019, and this yielded 14 papers and two videos. The general list of RAN papers was checked for any documents directly relevant to formal education and yet not included in the specific RAN EDU web page. This check resulted in the addition of three more documents (including the Manifesto for Education). Although this is not a longitudinal study, the papers were placed and analysed in chronological order to give a sense of the natural progression of the group and for any discursive changes and patterns over time to be discerned more clearly. Discourses matter as they form both the content and the context for social constructions, and their analysis enables us to understand the meanings attributed to PVE-E, what is considered as an appropriate response and, conversely, what should be avoided, or what is notably absent in the discourses. Although the coding scheme that emerged after the initial coding procedure (available upon request), and the analysis that ensued, brought up several themes and subthemes, due to space constraints, the emphasis here will be on definitions and subjectpositionings.

In addition to the primary method of discourse analysis of outputs (texts and videos), and in order to gain a better understanding of the institutional culture and procedures, I complemented these findings with desk-based collection of information such as charters, rules of procedures and policy legislation, participant observations from a two-day RAN EDU session held in 2019, and discussions with other RAN EDU 
members who have participated in such sessions. Despite the limited nature of the ethnographic observations, they are included here as they facilitate our understanding of how institutional cultures 'are being (re)produced "on the ground"' (Krzyżanowski, 2011: 283) - they allow access to negotiations, communicative patterns, 'inside' procedures and everyday practices within an organization that would not have been possible with only an analysis of formal texts. The section that follows is a critical engagement with the various activities and practices of RAN EDU.

\section{Mapping activities and practices: How does RAN EDU work?}

Although the EC launched RAN in 2011, it was only in 2015 that it became more active in the field of education. Following its Manifesto for Education - Empowering Educators and Schools (2015a), which was drafted after a large meeting with 90 educators in Manchester in March 2015 and set out the general framework on the role of education in PVE, RAN EDU had its first meeting in November of the same year, in Prague. RAN EDU focuses on:

better equipping teachers and the school system so they can play a crucial role in preventing radicalisation. The aim is to raise awareness of the topic, but also to empower and build capacity to prevent and deal with radicalisation in educational settings. (RAN, 2015b: 1, emphasis added)

Raising awareness, empowering and building capacity are mainly done through the working group meetings. The meetings bring together what they call 'front-line' or 'first-line' educators and practitioners, such as teachers, school principals, NGO representatives, policymakers and academics, to address 'specific issues related to violent extremism, and exchange with experts on new insights into tackling radicalisation' (RAN, 2016f: 1). The rationale is that people meet and share expertise on what they refer to as 'best practices', and get 'inspired' (a term used frequently) to go back to their profession and adopt some of these practices, while building new, long-term relationships.

Although the RAN EDU website does not so far include a compiled list of all the meetings related to education (or its participants), according to the 'rules of procedure', each group should have on average four meetings per year, these should last two days and should bring together around 35 members or participants representing at least ten different member states. There can also be joint meetings involving more than one working group, and the fact that one of RAN EDU's first joint meetings took place with RAN POL, the working group on police and other law enforcement officials (in 2017), is telling with regard to the connection ascribed to education and security.

The RAN Centre of Excellence (RAN CoE) was created in 2015 to better coordinate these activities by offering logistical, technical and administrative support. Management of the RAN CoE is led by RadarEurope, a Dutch private consulting company, and is financed by the EC, in particular the Internal Security Fund - Police. RAN CoE claims to develop 'state-of-the-art knowledge' (RadarEurope, n.d.). Indeed this is what it is supposed to be doing, as it has been placed in a key position of agenda-setting power: one of its tasks is to provide the EC with research gap analyses and shape the development of research programmes such as Horizon 2020. All issues related to RAN, RAN CoE and their connection to the EC are governed by the RAN Charter (RAN, n.d.a) and the RAN Rules of Procedure (RAN, n.d.b). Yet both these documents are often ambiguous (perhaps intentionally so, to maintain flexibility). For 
example, it is made clear that a 'member' (defined as a 'very experienced stakeholder') is more privileged than a 'participant' of the groups, but there is no clear indication as to the process or who ultimately decides on this and how.

Since its launch, RAN EDU has created frequent activities in order to support and promote its PVE-E agenda, including participation in the annual RAN high-level conference as well as the core working group meetings, bringing together more than 500 practitioners, such as educators, policymakers and NGOs. After the working group meetings an ex-post paper is produced, the aim of which is to present lessons learned, and to share expertise, follow-up activities and evidence-based recommendations. These are often authored by staff members of RAN CoE (even if they do not have any academic or first-hand expertise as teachers or educators). There are also 'Issue and Policy' papers, some of which are commissioned to academics to author. The latter are often much better in quality, in that arguments tend to be substantiated with some reference to empirical evidence and they are reviewed by an internal editorial board prior to publication (as we shall see later, some published ex-post papers, especially those prior to 2017, are rife with spelling or grammatical errors, giving the impression that due quality assurance was not applied). Two of the documents that are seen as milestones by RAN EDU are the Manifesto (RAN, 2015a) and the recent policy paper on Transforming Schools into Labs for Democracy (RAN, 2018d). RAN CoE also produced two videos on education in 2018, one on building resilience among children and one on conducting difficult conversations in the classroom. The topics of the working group meetings (and therefore the related outputs) are varied, and so far include themes such as the role of education, empowering teachers, the role of school principals, the need for cooperation with other partners, polarization management, school drop outs and media literacy. Whereas in the first two years the focus of the outputs was predominantly secondary education, from 2018 onwards, the focus expands to include papers on primary education (RAN, 2018c, 2018e) and higher education (RAN, 2018a).

Dissemination of the outputs largely depends on the participants willingly sharing them with their networks, and on educators visiting the website to access them or subscribing to the general monthly RAN newsletter. As of March 2019, the newsletter has around 5,000 subscribers, RAN's Twitter account has 6,170 followers and its Facebook account has 3,617 subscribers. It is not clear how many of these people have subscribed or followed specifically for the education aspect of RAN's work. These numbers are substantial, although perhaps not as high as one may expect, given that this involves all the working groups and a network representing the European Union comprised of 28 states and an estimated population of 513 million (at the time of writing). Arguably, the core mode of operation and impact of RAN EDU is through its working group meetings.

Attendance at the working group meetings is by invitation only, and there is no transparent process as to who makes the decision about who gets invited and how this decision is made. Although often there is a mix of both old and new participants, this does raise the question of whether it remains an open enough space for bottom-up participation if someone who does not have extensive networks or the relevant contacts would like to attend. The invitation-only process also means that the participants may be reluctant to express their views if these will be perceived as 'too critical'. A RAN EDU participant who raised strong concerns during a meeting has since then never been invited back, and questioned whether this was due to a lack of sufficient critical engagement with the radicalization agenda. They emphasized the need for more critical research and critical reflection on RAN's own practices: 
I think it would be good if the RAN network could have spaces for sharing practice and ideas and for research, including critical research ... Of course, key here is also a critical appraisal of RAN's own approach to these issues and to inviting critical reflection on the question of radicalisation. More space for thinking, dialogue and reflection would probably be welcome in this field. (Personal correspondence, 10 April 2019, emphasis added)

The lack of evaluation, as well as a lack of 'appetite for looking thoroughly' into alternatives suggested, was also strongly echoed by another participant:

Evaluation is postponed and repeating suggestions for systematizing the evaluation of WG[working group]-outcomes are not taken up. In general: RAN seems to be hesitant about self-evaluation of the WG-construction. While this format is invented as a reaction to particular threat, it might need some revision in this day and age ... To this date, I see no appetite for looking thoroughly into this. (Personal correspondence, 12 April 2019)

Nevertheless, it is important to note that the atmosphere of the working group meetings is a friendly one, and often involves devoted, enthusiastic and wellintentioned individuals who have often been working on formal education for most of their professional lives. As one participant put it, the meetings were a source of 'emotional support for one another when confronted with serious challenges' (personal correspondence, 12 April 2019). There seems to be a particularly strong rapport with those being invited more often, calling themselves 'veterans' and having their own insider jokes and code words. However, this familiarity too can backfire, as some individuals who do have a more critical approach do not always feel comfortable raising issues directly, or even when they do, there is at most a verbal acknowledgement but the status quo remains largely unchanged. The same participant was concerned that the group had become too close and that 'this might go at the cost of critiquing each other ... [it's] time for new blood, new people to break the build-up [of] routine'.

The diversity of participants can also be questioned. For example in the February 2019 meeting in Dublin, there were 13 participants (excluding the chairs and two RAN CoE staff members) from seven countries of the 28 in the EU. All seven countries were located in north-western Europe. Although one may argue that this is because most Islamist terrorist attacks occur in this part of the EU, there are other forms of violent extremism, in particular from the far right that is on the rise across the EU. Furthermore, it is not only countries such as Germany, France and Denmark that have seen a rise in anti-immigration sentiments, anti-Islamic rhetoric and Euroscepticism. In countries such as Hungary, Slovakia, the Czech Republic, Greece and Cyprus, significant electoral gains have been made by nationalist and far-right parties. Diversity is not just important in terms of including a range of opinions and experiences from minority or marginalized groups, as well as from countries that are not the strongest economic countries in the EU, but also in terms of the consequences this has on the scope of impact of the events. Lack of participation from a diverse pool of countries in the EU essentially translates to limiting the geographical scope of impact to those few countries, especially given that there are usually no follow-up activities between the members after the meetings.

In addition to the papers, there is also an evolving Collection of Approaches and Practices, with a chapter devoted to education projects. Yet it remains unclear 'which of these RAN EDU perceives as examples of "best practices" and what actually constitutes such practice', especially as there is a caveat that states that these do not have a 
label of EC/RAN approval, but are rather meant to offer information and inspiration (Christodoulou and Szakács, 2018: 39). Essentially, and perhaps unsurprisingly, this means that the projects featured and recommended, both in the RAN Collection and the papers, are those that people invited in the first place are involved in or acquainted with due to their own personal networks, rather than a result of in-depth, evidencebased and systematic appraisals.

These findings are not limited to the RAN EDU group but seem to be part of a wider structural weakness reflecting the way that RAN was set up. According to evidence included in a study commissioned by the European Parliament's Committee on Civil Liberties, Justice and Home Affairs, 'RAN is lacking a structured instrument to monitor how participants disseminate the good practices they picked up during the workshops into their own organizations' (European Parliament, 2017: 64). Kundnani and Hayes (2018: 21) also strongly criticize the lack of an external scrutiny mechanism 'outside of the self-selecting confines of the EU's expert networks'. There seem to be three related problematic practices here: lack of adequate quality assurance mechanisms; the closed nature and self-legitimization of the groups; and the fact that the groups act as channels of policy transfer where controversial or potentially problematic member state policies are actually imported into RAN and then disseminated to an EU level through RAN. This policy development process runs the risk of transferring 'the coercive and problematic elements' of these policies 'while ignoring the questions of fundamental rights, due process and accountability that are festering in many member states' (Kundnani and Hayes, 2018: 22). This becomes especially disconcerting with regard to the UK's Prevent strategy, which, despite being highly criticized by human rights organizations, is often viewed by top EU officials as a 'best practice model in Europe', with government departments even relied upon to run P/CVE programmes on an EU level (for example, the European Strategic Communications Network is based on the consultancy services and expertise of the UK Home Office's Research, Information and Communications Unit; Hooper, 2017). These problematic practices are further illustrated by a closer investigation of the discursive terrain of RAN EDU, to which we will now turn.

\section{The discursive terrain of RAN EDU}

\section{Normative emphasis and lack of scientific evidence}

The analysis of RAN EDU outputs such as manifestos, policy papers, ex-post papers and videos has shown that they remain highly normative, rather than offering practical advice on how educators can replicate certain 'good' or 'best' practices (both terms are used) or concrete examples that teachers, for instance, can adapt into their everyday classroom interactions. This is not something exclusive to RAN but reflects the dominant trend of other international organizations, partly attributed to the lack of definitive empirical research on what works and the thorny issue of attributing success to projects that are preventative in nature (Christodoulou and Szakács, 2018). Readers merely get a flavour of the different types of initiatives, and are being told what they should be doing, while difficult questions are glossed over. For example, a guide on training programmes for schools suggests that educators should: 'Ask providers of other training programmes how they operationalise the training goals and how they evaluate to what extent the goals have been reached' (RAN, 2017a: 18). One would expect that this is the place where teachers would come to find this kind of information. At times, examples are given with no links, no appraisal and no explanation, and it 
is not clear what the educator can gain from them. This is further illustrated by an example given in a paper on how to deal with young people returning to school in Europe from Syria or Iraq:

Under daesh [sic], children receive ideological training from the age of nine, and boys even receive weapons training. In Aarhus (DK), a screening tool for different age groups is under development:

- 9 months-1 year

- 1-6 years

- 6-12 years

- 12-18 years. (RAN, 2017c: 7)

There is no reference to where one can get more information about the 'screening tool', and it is not evident why it is included if it has not been completed, let alone 'tested'. The implicit normative suggestion is that such 'screening tools' are included as a good practice example, but there is no explanation as to why these are needed (what is their link to education?) or any evidence of their effectiveness. More importantly, it is not clear if screening 9-month- or 24-month-old babies is something feasible, let alone desirable.

The scientific quality of some of the ex-post papers is highly questionable: papers are not well-researched and sweeping, bold claims are made without solid evidence to back them up, apart from personal opinions (after 2017, the quality seems to have improved, with some papers presenting evidence, although their reliability varies significantly). Certain approaches are presented as 'effective', 'successful', 'promising', 'inspirational' or 'best practices' without recourse to scientific research; often the evidence given for their inclusion and their choice over other projects is that participants 'were impressed' with the presentation about them (RAN, 2016a: 4). For example, in a 2016 ex-post paper on the empowerment of teachers, none of the promising approaches have any reference to scientific studies or provide any concrete evidence as to their effectiveness in relation to PVE. This valorization is value- and power-laden, as these discourses act as forms of a Foucauldian governmentality and a force for policy change (Gillies, 2013). This is profoundly disconcerting when such projects may be taken as 'evidence' and reproduced or adopted by educators, schools, international organizations and networks, and NGOs.

\section{Exclusive, essentializing and problematic language and visuals}

The language used is also not unproblematic. Terms used essentialize both children and societies - for example, 'resocializing returnee children into Western society' (RAN, 2017c: 8). There are instances where the language used more resembles a marketing strategy in need of convincing consumers of the urgency and desirability of this product. For example: 'This will help ensure that young people, parents and families buy into this agenda' (RAN, 2015a: 4); young people need to be 'bought into democracy and fundamental rights' (RAN, 2016b: 4). In these instances, one can see why some of the initiatives of international organizations have been criticized for being patriarchal and neocolonial, and for trying to replace one form of propaganda with another (see the discussion on critical approaches above). One would also expect to see gender-sensitive and inclusive linguistic practices, avoiding sexist phrases where women are excluded, such as: 'Is the teacher a superman?' (RAN, 2016a: 3, emphasis added); 'the teacher finds his strength. The focus is on his own personality and capacity as leader in the classroom' (ibid.: 5, emphasis added). Interestingly, in both videos, all 
the speakers are white, and when images of what seems to be a 'radicalized' Muslim family appear, gender stereotypes abide, with the female members standing and wearing a veil while the men, one on each side, are standing, one with a gun and the other with a bullet chain around his neck (RAN, 2018h).

\section{Inconsistent terminology}

The terms 'extremism', 'violent extremism', 'radicalization' and 'violent radicalization' are used interchangeably, both across and within documents, and have neither clear nor consistent definitions. PVE is sometimes also used synonymously with CVE; sometimes they are treated as being different but with no explanation as to what their definitions or differences are (for example, RAN, 2017c); sometimes they are used together as PCVE (for example, RAN, 2018a). One of the more nuanced papers on terminology is one that was co-authored by several participants of a workshop that took place in March 2017 in Helsinki, and emphasizes that radical ideas are not bad per se and have been in fact the triggers for positive societal change:

... a healthy portion of radicalism is not cause for concern ... Without radicals challenging the system and the status quo, today there would be no women's rights, no fundamental rights and no environmental policy ... Schools should be the place to express radical ideas and even extreme opinions. But this should take place in a safe, pedagogical environment, guided by trained teachers. (RAN, 2017a: 5)

\section{What is the role of schools and teachers?}

Schools and teachers are constructed as having crucial agency, being 'on the front-line to help identify and safeguard youngsters at risk of radicalization, and to partner in preventive efforts' (RAN, 2015a: 1). Although there is no mention of the words 'legal duty' (as in the UK, for example), teachers are pressured to act. Throughout the various outputs, teachers are told that they play a 'key role' in this, that they have a 'responsibility' and that they 'need to invest' (time spent on training is presented as investing) and to 'act on this'. An evident responsibilization of teachers is taking place as agents of prevention, binding them with a moral and professional obligation for ensuring state security. The implication of such discourses is the positioning of teachers as ultimate determinants of the success of prevention, and by implication also as possibly liable for failure, thereby individualizing security and shifting responsibility away from the state (see also Done and Murphy, 2018; Torrance, 2017). Such positionings dovetail with neo-liberalist agendas of state governance that conveniently ignore structural factors and injustices that are well beyond the control of the teacher. As Peeters (2013: 584) observes, key to such modes of governance 'is the view that citizens have their own responsibility in preventing social harms'.

On a similar line, schools are told that they 'should make "prevention" work fundamental and a priority' (RAN, 2015a: 2). Interestingly, within the same document there is implicitly a recognition that contradicts this idea, suggesting that this is not what schools should primarily be about: 'Schools can be a valuable actor in prevention, but they are schools in the first place' (ibid.: 3 ).

This confusion and ambiguity is partly a consequence of the RAN importing, absorbing and regurgitating policies from other countries, inevitably inheriting some of their flaws and weaknesses, as well as negative publicity. The findings confirm arguments made by scholars (such as Kundnani and Hayes, 2018) regarding the UK influence, yet the picture that emerges is not one of simple exportation. Instead, 
for example, there is an ambiguity and inconsistency in the way the UK's Prevent policy in schools is referred to, and a caution with the way teachers' role in identifying students 'at risk' is presented, in an attempt to avoid receiving the same criticism. This explains why we see, on the one hand, the UK's Prevent policy being mentioned as an 'inspiring' example and a related Prevent school checklist even being included in the Appendix (RAN, 2016d), papers referring to studies commissioned by the UK government as a best practice and 'required reading' (RAN, 2018b), and an almost identical use of dominant discourses to those in Prevent - for example, students that are 'vulnerable', 'at risk', in need of 'safeguarding' (see UK Home Office, 2019). On the other hand, the role of the teacher and the school is sometimes anchored in a more critical perspective, perhaps included more so as to pre-empt any criticism, rather than because they want to dissociate themselves from the UK model or take a clear stance against it. For example, they state that teachers are not spies, that 'in the UK it is even statutory to report' and that teachers have expressed concern about losing the trust of their students and making them 'afraid to participate in classroom conversations' as a result (RAN, 2016a: 3, emphasis added). In a later document, they again seem to be on the fence, suggesting teachers 'must refer' and describing the benefits of such legislation, followed by a description of the harm that can occur 'when introduced inappropriately' without further clarification as to what 'inappropriately' could mean (RAN, 2017c: 5-6).

There is also a persistent discourse of empowerment of teachers: a strong assumption that if they are empowered, then they will be able to 'truly prevent violent extremism' (RAN, 2015a: 1). There is no clear explanation as to how RAN EDU thinks teachers can and should be empowered, or what they mean by empowerment. Reference to so-called promising practices in one of their papers leaves the reader with little idea of how to replicate this. The following is from what is described as a 'promising' and 'effective' example of teacher empowerment at a school in Antwerp:

[A school] witnessed infiltration by radical islamists and there were conflicts around religios [sic] symbols. Demonstrations and clashes took place outside the school and the school was in the national and internation [sic] press. The school took serious measures by banning the veil on the one hand, andat [sic] the same [sic] invested seriously in the staff with an intensive programme in personal communication. The teachers learned to listen to themselves. How to deal with emotions that might not help if they result in a reaction by the teacher? The teacher needs to go beyond reactivity. It starts by how the body reacts to emotions. (RAN, 2016a: 5)

With this example, it is also not clear if the assumption is that 'banning the veil' is the best way to go or not, and why.

Throughout the outputs, there tend to be preamble statements expressing an appreciation of how certain approaches can do more harm than good, yet shortly afterwards these practices are still presented as desirable, despite their dangers. In other words, there is a type of 'we know it, we want you to know that we are aware of it, but you need to do it anyway' language. We have already seen that for teachers, there seems to be a discursive oscillation from providing a safe space to actually acting as security agents by monitoring, identifying and reporting young people who may potentially become dangers to others. There is an assumption that it is possible to have both an 'identifying' role and also to keep students' trust and make them feel comfortable to discuss sensitive and controversial issues in 'a safe and open way' (RAN, 2015a: 1). Teachers are encouraged to hold difficult conversations and not shy 
away from sensitive topics, but are not told how to do so when it comes to specific topics of violent extremism.

\section{How are students represented in the discourses?}

The typical 'victim-villain' binary image of students was not prevalent in the RAN EDU outputs. Rather, there is a 'victim-agent' binary. Instead of villains, on the one hand, students are constructed as subjects at risk, vulnerable, potential victims in need of protection and safeguarding, while, on the other hand, there is weight given to involving students in prevention initiatives, following the international context (see the Introduction). Scholars have already cautioned against this global trend, given that it risks instrumentalizing and responsibilizing youth to pursue security agendas (Christodoulou and Szakács, 2018; Sukarieh and Tannock, 2018). The reasoning ranges from students being presented as having the 'potential' to prevent their peers from being drawn to violent extremism (RAN, 2016c: 1), to at other times saying that it is because students best know how to use social media, or that involving them will make them feel empowered. Another paradox is that students are, on the one hand, presented as knowing better, and, on the other hand, being recruited by violent extremists and radicalized online exactly because they lack media literacy:

Who knows better how to use social media, how to write an alternative story for people their own age? It's students who should be part of the solution, when it comes to providing alternatives for the messages extremists spread via social media. With their knowledge of social media and their creativity, they are the ones who should be in the driving seat ... Students are empowered, by making them responsible for their own environment. (RAN, 2015b: 4, emphasis added)

The discourse of 'resilience' to violent extremism is widespread in almost all the documents. The understanding of resilience mobilized needs to be interrogated for three reasons. First, it reflects a particular understanding of radicalization as a linear ideological process that is unsubstantiated by recent research on the causes of violent extremism. Second, it presents a simplistic understanding of resilience; the linear assumption is that teacher trainers will train teachers on which competencies are required, the students will develop these competencies (like antibodies), and this will then act as a defence system - that is, as resilience against the seemingly inevitable virus of terrorist propaganda, violent radicalization and extremism. The underlying logic is that if students are equipped with certain skills and values, such as democratic and citizenship skills, 'fundamental values', media literacy and critical thinking skills, then they will not fall victim to violent extremist narratives. In addition to the fact that constructing 'vulnerable' and 'resilient' subjects has the risk of 'pathologising dissenting students' (O'Donnell, 2016: 70), the use of the term 'resilience' presents violent extremism as an inevitable danger, thereby actually empowering and amplifying it (Christodoulou and Szakács, 2018: 43). Efforts are then directed not at educating students but at preparing them to be 'resilient' to a specific threat, as if in a state of war. The third critique of the resilience discourse is related to the ideological assumptions within which it is embedded. Resilience focuses on preparing students as individuals, rather than paying attention to the structural disadvantages, injustices, exclusionary practices and inequalities that are pervasive, and have been known to be push factors for violent extremism.

In fact, whenever injustices are mentioned in the outputs, they are either reduced to individual 'sentiments' of injustice that the teacher can and should help to remedy, 
or the adjective 'perceived' is used (that is, they are 'perceived' injustices), denoting that it is a matter of changing individual perceptions and not about something 'real'. There is little appreciation of how often students have very little power against the systemic inequalities they have to face in their everyday lives, but instead a focus on neo-liberalist concepts of self-reliance, responsibility and individual coping strategies. The issue of violent extremism (and its prevention) is therefore transformed 'into a problem of "self-care"' (Lemke, 2001: 201). There seems to be a notion that those children who become extremists are simply those who have not been taught how to cope with life, so the solution lies in teaching children how to be better able 'to cope' with stress and life's obstacles, and to develop self-regulation skills even from a primary school age (RAN, 2018b), rather than in addressing some of the injustices that led to these obstacles in the first place.

\section{Conclusion}

For any organization to truly improve, it needs to be open to receiving constructive feedback, let alone when the issues at stake are education and violent extremism. These are two sensitive issues regarding a field of practice and scholarly work that is still at an embryonic stage, and therefore any implications can help determine and shape it in the long term. The present study has deepened our understanding of European responses to preventing violent extremism, and has shown that interrogating policy texts and practices is vital to exposing the often-masked workings of discursive power but also the dangers present when international organizations lack external mechanisms that ensure quality assurance, transparency and positive impact.

Through an analysis of organizational practices and 19 outputs on the topic of education and violent extremism, the study has provided ample evidence of problematic assumptions and practices that might be counterproductive, and therefore spaces for improvement. Taken-for-granted understandings of 'radicalization' and 'resilience' need to be questioned, as does the assumption that it is possible to detect young people who are 'vulnerable' and 'at risk'. The findings show that RAN outputs are not immune from the ambiguous, patriarchal and inconsistent terminology that often characterizes this field. Although part of this can be attributed to the contested, diverse, evolving and complex nature of the topic of violent extremism (see Christodoulou and Nesterova, 2019), issues can also be traced back to particular neo-liberalist ideals or deeply entrenched yet empirically weak assumptions held about the kind of practices considered appropriate for teachers to enact. Rather than focusing on the individual traits of an ideal teacher and an ideal student, perhaps it is high time to explore whether there is a 'school to terror' pipeline (Duckworth, 2016) - that is, if there are any aspects of the curriculum, school culture and educational policies that are exacerbating the problem, and what society can and should do about it.

\section{Acknowledgements}

Some of the research for this article was conducted as part of a project funded by the German Federal Ministry of Education and Research entitled Preventing Violent Extremism through Education: Discourses and Practices. I would like to thank Simona Szakács, Felicitas Macgilchrist and two anonymous reviewers for their feedback and suggestions. 


\section{Notes on the contributor}

Eleni Christodoulou is a postdoctoral researcher in peace and conflict at the Georg Eckert Leibniz Institute for International Textbook Research, Germany. She completed an ESRC-funded PhD in political science on the 'Politics of Peace Education' at the University of Birmingham, UK. Eleni has cooperated with international organizations on matters related to Target 4.7 of the Sustainable Development Goals, and was principal investigator of a project on international and German approaches to PVE-E. She has published on history textbooks in conflict societies, education and violent extremism, and education for sustainable development.

\section{References}

Barnett, M. and Finnemore, M. (2004) Rules for the World: International organizations in global politics. Ithaca, NY: Cornell University Press.

Brown, K.E. and Saeed, T. (2015) 'Radicalization and counter-radicalization at British universities: Muslim encounters and alternatives'. Ethnic and Racial Studies, 38 (11), 1952-68.

Busher, J., Choudhury, T., Thomas, P. and Harris, G. (2017) What the Prevent Duty Means for Schools and Colleges in England: An analysis of educationalists' experiences. London: Aziz Foundation.

Christodoulou, E. and Nesterova, Y. (2019) 'Violent extremism: Types, implications and responses'. In Leal Filho, W., Azul, A.M., Brandli, L., Özuyar, P. and Wall, T. (eds) Peace, Justice and Strong Institutions: Encyclopedia of the UN Sustainable Development Goals. Cham: Springer. Online. https://tinyurl.com/uzx7w7g (accessed 10 February 2020).

Christodoulou, E. and Szakács, S. (2018) Preventing Violent Extremism through Education: International and German approaches. Braunschweig: Georg Eckert Institute. Online. https://repository.gei.de/handle/11428/297 (accessed 30 November 2019).

Davies, L. (2016) 'Security, extremism and education: Safeguarding or surveillance?'. British Journal of Educational Studies, 64 (1), 1-19.

Davies, L. (2018) Review of Educational Initiatives in Counter-Extremism Internationally: What works? (Report 5). Gothenburg: Segerstedt Institute. Online. https://tinyurl.com/vzm46ar (accessed 30 November 2019).

Done, E.J. and Murphy, M. (2018) 'The responsibilisation of teachers: A neoliberal solution to the problem of inclusion'. Discourse: Studies in the Cultural Politics of Education, 39 (1), 142-55.

Duckworth, C.L. (2016) 'Is there a school to terror pipeline? The case of France'. Journal of Contemporary Issues in Education, 11 (1), 86-96.

European Commission (2015) The European Agenda on Security. Strasbourg: European Commission. Online. https://tinyurl.com/w4f5cnr (accessed 30 November 2019).

European Parliament (2017) The European Union's Policies on Counter-Terrorism: Relevance, coherence and effectiveness. Brussels: European Parliament. Online. https://tinyurl.com/tgd9yxz (accessed 30 November 2019).

Finnemore, M. (1993) 'International organizations as teachers of norms: The United Nations Educational, Scientific, and Cultural Organization and science policy'. International Organization, 47 (4), 565-97.

Gillies, D. (2013) Educational Leadership and Michel Foucault. London: Routledge.

Heath-Kelly, C. and Strausz, E. (2019) 'The banality of counterterrorism "after, after 9/11"? Perspectives on the Prevent duty from the UK health care sector'. Critical Studies on Terrorism, 12 (1), 89-109.

Holmwood, J. and O'Toole, T. (2018) Countering Extremism in British Schools? The truth about the Birmingham Trojan Horse affair. Bristol: Policy Press.

Home Office (2019) 'Statutory guidance: Revised Prevent duty guidance: For England and Wales'. Online. https://tinyurl.com/u4sutys (accessed 30 November 2019).

Hooper, S. (2017) 'EU embraces UK counter-extremism policies despite human rights concerns'. Middle East Eye, 5 May. Online. https://tinyurl.com/uh2fn2t (accessed 30 November 2019).

Krzyżanowski, M. (2011) 'Political communication, institutional cultures and linearities of organisational practice: A discourse-ethnographic approach to institutional change in the European Union'. Critical Discourse Studies, 8 (4), 281-96.

Kundnani, A. (2012) 'Radicalisation: The journey of a concept'. Race and Class, 54 (2), 3-25. 
Kundnani, A. and Hayes, B. (2018) The Globalisation of Countering Violent Extremism Policies: Undermining human rights, instrumentalising civil society. Amsterdam: Transnational Institute. Online. www.tni.org/files/publication-downloads/cve_web.pdf (accessed 30 November 2019).

Lemke, T. (2001) "'The birth of bio-politics": Michel Foucault's lecture at the Collège de France on neo-liberal governmentality', Economy and Society, 30 (2), 190-207.

Mattsson, C., Hammarén, N. and Odenbring, Y. (2016) 'Youth "at risk": A critical discourse analysis of the European Commission's Radicalisation Awareness Network Collection of approaches and practices used in education'. Power and Education, 8 (3), 251-65.

Mudde, C. (2016) On Extremism and Democracy in Europe. London: Routledge.

Neumann, P.R. (2013) 'The trouble with radicalization'. International Affairs, 89 (4), 873-93.

Nguyen, N. (2014) 'Education as warfare? Mapping securitised education interventions as war on terror strategy'. Geopolitics, 19 (1), 109-39.

Novelli, M. (2017) 'Education and countering violent extremism: Western logics from south to north?'. Compare: A Journal of Comparative and International Education, 47 (6), 835-51.

O'Donnell, A. (2016) 'Securitisation, counterterrorism and the silencing of dissent: The educational implications of Prevent'. British Journal of Educational Studies, 64 (1), 53-76.

Panjwani, F., Revell, L., Gholami, R. and Diboll, M. (eds) (2018) Education and Extremisms: Rethinking liberal pedagogies in the contemporary world. London: Routledge.

Peeters, R. (2013) 'Responsibilisation on government's terms: New welfare and the governance of responsibility and solidarity'. Social Policy and Society, 12 (4), 583-95.

RadarEurope (n.d.) 'RAN Centre of Excellence'. Online. www.radareurope.nl/themes/ran-coe/ (accessed 28 April 2019).

RAN (Radicalisation Awareness Network) (n.d.a) Charter of Principles Governing the Activities of the RAN Center of Excellence. Amsterdam: Radicalisation Awareness Network.

RAN (Radicalisation Awareness Network) (n.d.b) Rules of Procedure Governing the Activities of the RAN Center of Excellence (RAN CoE). Amsterdam: Radicalisation Awareness Network.

RAN (Radicalisation Awareness Network) (2015a) Manifesto for Education - Empowering Educators and Schools. Amsterdam: Radicalisation Awareness Network.

RAN (Radicalisation Awareness Network) (2015b) 'Ex post paper: RAN EDU kick-off meeting'. Online. https://tinyurl.com/vfhndlu (accessed 28 November 2019).

RAN (Radicalisation Awareness Network) (2016a) 'Ex post paper: Empowering and supporting teachers: Pedagogical role requires time and training'. Online. https://tinyurl.com/tpm86n5 (accessed 28 November 2019).

RAN (Radicalisation Awareness Network) (2016b) 'Ex post paper: School leaders and prevention of radicalisation: Setting the conditions for a safe and democratic environment'. Online. https://tinyurl.com/rkuxxy8 (accessed 28 November 2019).

RAN (Radicalisation Awareness Network) (2016c) Involving Young People: Main lessons learned. Amsterdam: Radicalisation Awareness Network.

RAN (Radicalisation Awareness Network) (2016d) 'Ex post paper: The school needs partners'. Online. https://tinyurl.com/vhhujaq (accessed 28 November 2019).

RAN (Radicalisation Awareness Network) (2016e) 'RAN issue paper: The role of education in preventing radicalisation'. Online. https://tinyurl.com/y5vytnpj (accessed 28 November 2019).

RAN (Radicalisation Awareness Network) (2016f) 'The Radicalisation Awareness Network'. Amsterdam: Radicalisation Awareness Network. Online. https://tinyurl.com/w94at3v (accessed 18 December 2019).

RAN (Radicalisation Awareness Network) (2017a) RAN EDU's Guide on Training Programmes: Effective and confident teachers and other school staff. Amsterdam: Radicalisation Awareness Network.

RAN (Radicalisation Awareness Network) (2017b) 'Ex post paper: RAN POL and EDU meeting on "polarisation management"'. Online. https://tinyurl.com/tnb8swj (accessed 28 November 2019).

RAN (Radicalisation Awareness Network) (2017c) 'Ex post paper: Drop-outs and going back to school'. Online. https://tinyurl.com/rdypaoz (accessed 28 November 2019).

RAN (Radicalisation Awareness Network) (2017d) 'Ex post paper: Dealing with fake news, conspiracy theories and propaganda in the classroom'. Online. https://tinyurl.com/yb8fu4sn (accessed 28 November 2019).

RAN (Radicalisation Awareness Network) (2018a) 'Ex post paper: Free speech, extremism and the prevention of radicalisation in higher education'. Online. https://tinyurl.com/wr8xzje (accessed 28 November 2019). 
RAN (Radicalisation Awareness Network) (2018b) 'Ex post paper: Building resilience in the classroom using testimonials from victims and formers'. Online. https://tinyurl.com/rchws $3 \mathrm{v}$ (accessed 28 November 2019).

RAN (Radicalisation Awareness Network) (2018c) 'Ex post paper: Building resilience among young children raised in extremist environments - specifically child returnees'. Online. https://tinyurl.com/ux9zbqo (accessed 28 November 2019).

RAN (Radicalisation Awareness Network) (2018d) Transforming Schools into Labs for Democracy: A companion to preventing violent radicalisation through education (RAN Policy Paper). Amsterdam: Radicalisation Awareness Network.

RAN (Radicalisation Awareness Network) (2018e) 'Ex post paper: The role of primary education in preventing radicalisation: A realistic and optimistic perspective'. Online. https://tinyurl.com/y24opcnb (accessed 28 November 2019).

RAN (Radicalisation Awareness Network) (2018f) Preventing Radicalisation to Terrorism and Violent Extremism: Educating young people (RAN Collection of Approaches and Practices). Amsterdam: Radicalisation Awareness Network.

RAN (Radicalisation Awareness Network) (2018g) Holding Difficult Conversations: The classroom [video]. Online. www.youtube.com/watch?v=OnH7DY3uMlk (accessed 16 April 2018).

RAN (Radicalisation Awareness Network) (2018h) RAN Policy and Practice (Warsaw): Building resilience among young children [video]. Online. www.youtube.com/watch?v=DggONFHVA_w (accessed 1 October 2018)

Rizvi, F. and Lingard, B. (2010) Globalizing Education Policy. London: Routledge.

Shirazi, R. (2017) 'When schooling becomes a tactic of security: Educating to counter "extremism"'. Diaspora, Indigenous, and Minority Education, 11 (1), 2-5.

Sieckelinck, S., Kaulingfreks, F. and De Winter, M. (2015) 'Neither villains nor victims: Towards an educational perspective on radicalisation'. British Journal of Educational Studies, 63 (3), 329-43.

Sukarieh, M. and Tannock, S. (2018) 'The global securitisation of youth'. Third World Quarterly, 39 (5), 854-70.

Thomas, P. (2016) 'Youth, terrorism and education: Britain's Prevent programme'. International Journal of Lifelong Education, 35 (2), 171-87.

Torrance, H. (2017) 'Blaming the victim: Assessment, examinations, and the responsibilisation of students and teachers in neo-liberal governance'. Discourse: Studies in the Cultural Politics of Education, 38 (1), 83-96.

United Nations General Assembly (2015) Plan of Action to Prevent Violent Extremism. New York: United Nations. Online. www.un.org/en/ga/search/view_doc.asp?symbol=A/70/674 (accessed 14 November 2018).

Winter, C. and Mills, C. (2018) 'The Psy-Security-Curriculum ensemble: British Values curriculum policy in English schools'. Journal of Education Policy, 1-22. Online. https://tinyurl.com/wxk8zv9 (accessed 24 November 2019).

Wodak, R. and Krzyżanowski, M. (eds) (2008) Qualitative Discourse Analysis in the Social Sciences. Basingstoke: Palgrave Macmillan.

Youth4Peace (2016) 'About the Youth, Peace and Security Agenda'. Online. www.youth4peace.info/About_YPS_Agenda (accessed 10 December 2018). 